\title{
Preventing Lignin Condensation to Facilitate Aromatic Monomer Production
}

\author{
Wu Lan and Jeremy S. Luterbacher $\S^{*}$
}

\$Werner Prize 2019

\begin{abstract}
Lignin is the most abundant aromatic polymer in nature and as such is an attractive source of aromatic molecules. Efficient lignin utilization will also likely play a key role in the economic success and sustainability of biomass valorization schemes. However, traditional strategies for lignin isolation and depolymerization suffer from repolymerization issues, which result in low yield of low molecular weight fragments. This review summarizes the recent progress in lignin isolation and depolymerization methods that are able to limit lignin condensation and facilitate the high yield production of monomers and oligomers. A general trend in these methods is that condensation and repolymerization is prevented by trapping reactive intermediates during extraction or depolymerization by chemically stabilizing the $\beta-\mathrm{O}-4$ structure and/or its derivatives, or physically removing the separated lignin fragments from the reactor. We highlight the challenges and opportunities that these methods will face as they are further developed.
\end{abstract}

Keywords: Acetal · Biomass · Hydrogenolysis · Depolymerization · Lignin · Oxidation · Repolymerization

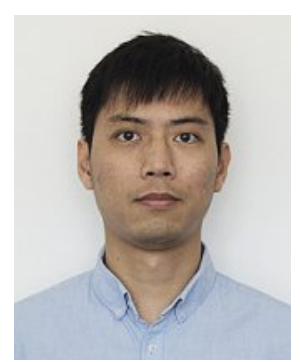

Wu Lan received a BSc and MSc in pulp and paper making engineering from South China University of Technology in 2009 and 2012. Then he joined Prof. John Ralph's group in the department of biological system engineering in University of Wisconsin, Madison and received his PhD degree in 2016. He moved to École Polytechnique Fédérale in Lausanne (EPFL) in the same year as a postdoctoral researcher in the Laboratory of Sustainable and Catalytic Processing led by Prof. Jeremy Luterbacher to work on catalytic depolymerization of lignin.

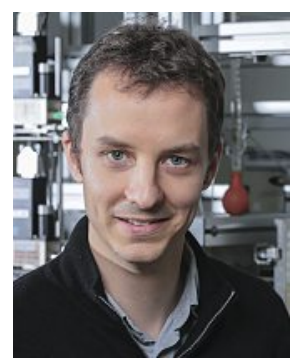

Jeremy Luterbacher was born in Switzerland in 1984 and received a BSc and MSc in chemical engineering from the École Polytechnique Fédérale in Lausanne (EPFL), Switzerland in 2007. He spent a year as a visiting scientist at the Massachusetts Institute of Technology in Jeff Tester's laboratory and then moved to Cornell University for a $\mathrm{PhD}$ under the supervision of Prof. Larry Walker. In 2012, Jeremy joined the University of Wisconsin-Madison as a Swiss National Science Foundation Postdoctoral Scholar under the supervision of Prof. Jim Dumesic. In 2014, Jeremy returned to EPFL as an Assistant Professor and head of the Laboratory of Sustainable and Catalytic Processing.

\section{Introduction}

Biomass is the second largest renewable carbon feedstock after atmospheric $\mathrm{CO}_{2}$. Depletion of fossil resources and the search for renewable alternatives in both the energy and chemical sectors has led to extensive research and development programs in biomass transformation. Lignocellulosic materials are the most abundant source of biomass and contain mainly cellulose, hemicellulose, and lignin. Unlike cellulose and hemicelluloses, which are carbohydrate polymers of 5- or 6-carbon sugars, lignin is an aromatic polymer of methoxylated phenylpropanoid units, accounting $15-30 \%$ by weight and $40 \%$ by energy of lignocellulose.[1] Due to its high energy content and aromaticity, lignin has attracted a lot of attention in the context of producing sustainable fuels and aromatic chemicals. Its biosynthesis occurs via oxidative radical coupling of $p$-coumaryl, coniferyl, and sinapyl alcohol (and tricin in the case of grass ${ }^{[2]}$ ), which are so-called 'monolignols', generating different types of $\mathrm{C}-\mathrm{C}$ and $\mathrm{C}-\mathrm{O}$ linkages between each phenyl propanoid sub-unit (Scheme 1).[3]

Depolymerization of lignin to aromatic molecules for use as an alternative to petrochemical feedstocks is an attractive route towards developing a sustainable chemical industry. However, the content of $\mathrm{C}-\mathrm{C}$ linkages within the lignin to be depolymerized significantly influences the yield of aromatic monomers. These $\mathrm{C}-\mathrm{C}$ linkages exist in native lignin, and can form during lignin isolation/fractionation and depolymerization. During the biosynthesis process known as lignification, the radical located at $\mathrm{C} \beta$ of a monolignol (IV, Scheme 1A) reacts most favorably with the radical at the phenolic $\mathrm{OH}$ position of another monolignol (I in Scheme 1A) to form the $\beta-\mathrm{O}-4$ linkage, which ends up being the most prominent linkage in lignin. However, the $C \beta$ position can also react with radicals generated at the $C 1, C 5$, or $C \beta$ positions (III, II or IV respectively, Scheme 1A) to form the so-called $\beta-\beta$, $\beta-1$ and $\beta-5$ linkages. Finally, two radicals at the $C 5$ positions can react together to form 5-5 linkages (II in Scheme 1A) (See the hypothetical hardwood lignin structure model in Scheme 1B). ${ }^{[4]}$ Overall, this leads to anywhere from 20 to $50 \% \mathrm{C}-\mathrm{C}$ linkages in the native structure of lignin for hardwoods and softwoods, respectively.[1c] Assuming the number of $\mathrm{C}-\mathrm{C}$ and ether linkages 
A

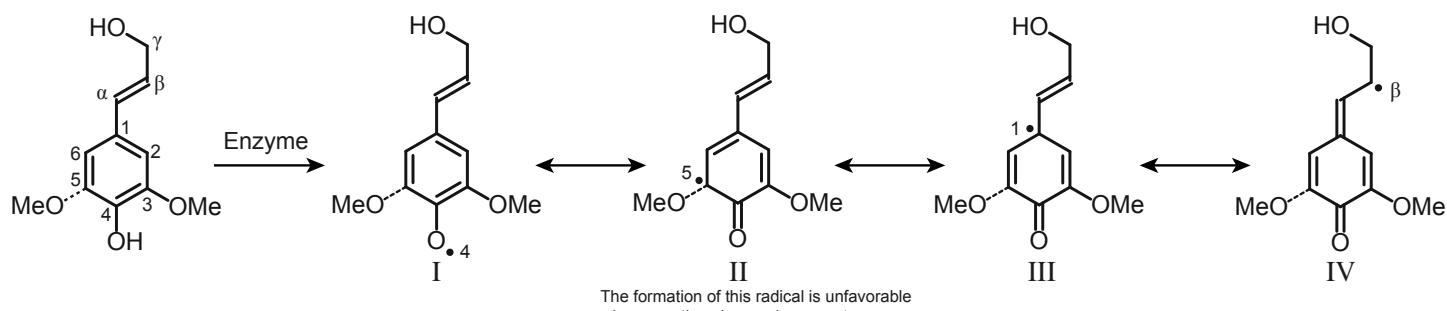

B

when a methoxyl group is present

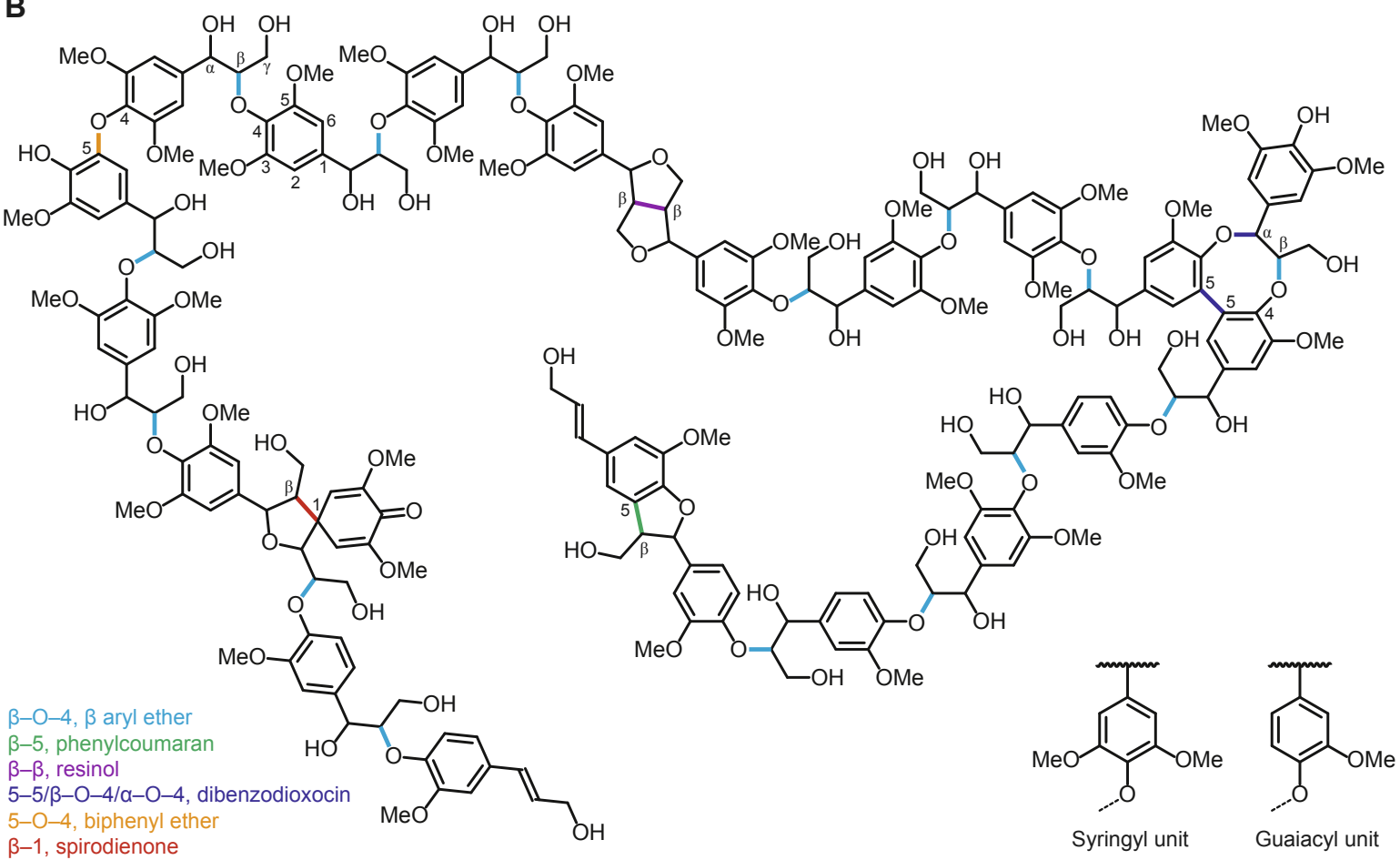

Scheme 1. Lignification process (A) and hypothetical hardwood lignin model (B). This model contains 21 monomers (both syringyl and guaiacyl units) illustrating different ether linkages $(\beta-\mathrm{O}-4, \alpha-\mathrm{O}-4$, and $5-\mathrm{O}-4)$ and $\mathrm{C}-\mathrm{C}(\beta-5, \beta-\beta, \beta-1$, and $5-5)$ linkages present between each unit.

are more or less randomly distributed throughout the lignin, this limits the theoretical monomer yield to about $25 \%$ for softwoods and $50 \%$ for hardwoods based on ether cleavage.

The situation is more complex for $\mathrm{C}-\mathrm{C}$ linkage formation during extraction and depolymerization. Scheme 2 shows the possible depolymerization and condensation mechanism of the $\beta-\mathrm{O}-4$ structure. ${ }^{[5]}$ Under solvolysis (temperatures above $80^{\circ} \mathrm{C}$ in an organic solvent) or acidic conditions, the $\alpha-\mathrm{OH}$ of the $\beta-\mathrm{O}-4$ linkage can dehydrate to form an unsaturated $\mathrm{C}=\mathrm{C}$ bond, which can readily repolymerize with other unsaturated bonds through a radical oligomerization (Scheme 2A). Under basic conditions, the $\beta-\mathrm{O}-4$ ether can be cleaved, followed by formaldehyde elimination to produce phenylacetaldehyde, which is an unstable product that readily condenses with nucleophiles (Scheme 2B). Lignin contains many such nucleophiles that can participate in this condensation, including the free positions on the aromatic rings. Furthermore, the free phenolic units can be deprotonated and generate even more nucleophilic sites on the aromatic ring at the positions that are ortho and para to the phenol group. A quinone methide intermediate can be formed through a similar mechanism (Scheme 2C). Then, the $\mathrm{C} \gamma-\mathrm{OH}$ can be eliminated as formaldehyde to form an enol ether, which can readily react with a nucleophile to form a $\mathrm{C}-\mathrm{C}$ linkage. ${ }^{[6]}$ Under acidic conditions, a possible lignin condensation mechanism involves the formation of a highly reactive benzylic carbocation by elimination of a protonated $\alpha-\mathrm{OH}$, similar to what occurs during solvolysis (Scheme 2D). This carbocation can react with the aforementioned nucleophilic carbanions (i.e. carbons on aromatic rings) to form $\mathrm{C}-\mathrm{C}$ linkages. Moreover, acidolysis of $\beta-\mathrm{O}-4$ ether linkages produces phenylacetaldehyde that can also lead to repolymerization by reacting with the aforementioned nucleophiles like lignin's aromatic ring positions (Scheme $2 \mathrm{E}$ ).

Lignin repolymerization systematically occurs in biorefineries as well as pulp and paper processes. This irreversible process significantly reduces possible applications and, thus, lignin's value. Despite this, and because of the difficulty of preventing this condensation, millions of tons of repolymerized and low value lignin are produced each year. In this context, developing methods that can prevent/limit condensation would greatly improve lignin utilization efficiency and increase the economic viability and environmental sustainability of biomass conversion processes. In recent years, significant efforts have been devoted to suppress the undesired formation of C-C linkages. Successful methods can be split into two general categories: (1) those that have focused on the in situ trapping of the reactive intermediates to convert them into stable molecules or (2) those focused on directly stabilizing the $\beta-\mathrm{O}-4$ ether linkages (either physically or chemically). Here, we provide a concise overview on the different methods that have successfully reduced $\mathrm{C}-\mathrm{C}$ bond formation within these two categories as well as discuss the challenges facing these methods and prospects for future development.

\section{Trapping Reactive Intermediates}

\subsection{Reductive Catalytic Fractionation of Lignocellulose}

Since many condensation reactions happen via nucleophilic additions on reactive intermediates (Scheme 2), one solution is to provide a nucleophile that will trap these reactive intermediates without impeding their depolymerization. This can be done by performing a direct hydrogenolysis on the native lignin in the 


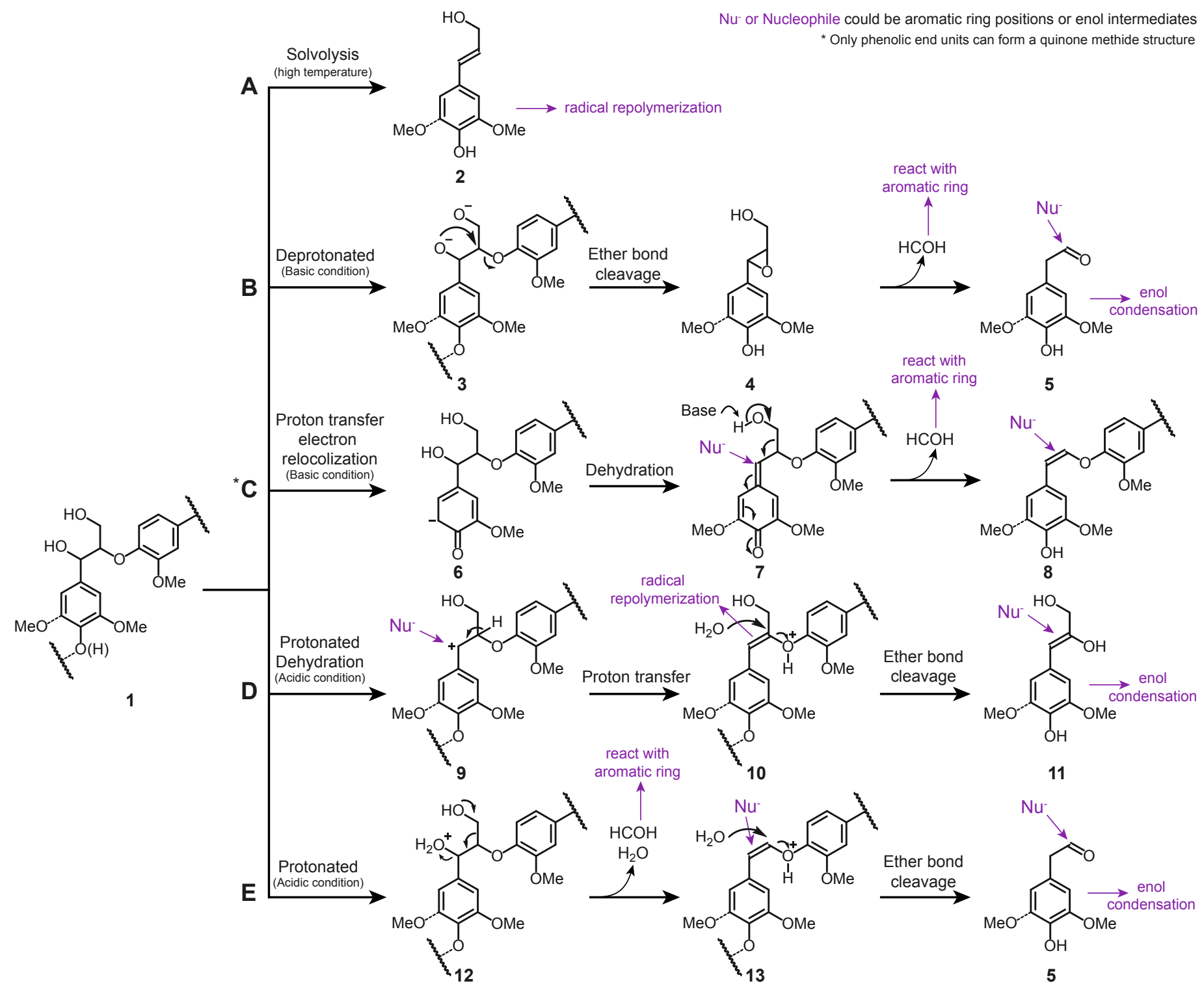

Scheme 2. Decomposition of lignin under neutral (A), basic (B and C) and acidic (D and E) conditions. The purple arrows indicate the possible repolymerization mechanisms involving the reactive intermediates depicted in the Scheme. Nu- represents a nucleophile. Adapted from refs [5b,c,6b,33].

lignocellulosic biomass matrix and/or performing this hydrogenation as lignin is being extracted, which is also known as reductive catalytic fractionation ( $\mathrm{RCF})$. RCF is a reaction that is performed at high temperature $\left(180-250^{\circ} \mathrm{C}\right)$ with a hydrogen donor (hydrogen, methanol, ethanol, or others) and a metal catalyst (homogenous or heterogeneous) all in the presence of untreated biomass. Ether bonds are easily cleaved under such conditions while the reactive intermediates (compound 2 , Scheme 2A) are also generated. However, under RCF conditions, these reactive intermediates react more favorably with molecular hydrogen activated by the catalyst than with the typical nucleophiles involved in condensation. In 1948, Hibbert pioneered the use of hydrogenolysis using Raney ${ }^{\circledR}$ nickel as catalyst on lignin related model compounds and woody biomass material and successfully isolated $27 \mathrm{wt} \%$ aromatic monomers based on Klason lignin. ${ }^{[7]}$ In later studies, different supported metal catalysts including $\mathrm{Ni},{ }^{[8]} \mathrm{Pt},{ }^{[9]} \mathrm{Pd},{ }^{[10]} \mathrm{Ru},{ }^{[9 b, 11]}$ and $\mathrm{Rh}^{[9 b]}$ were tested and proved to be highly effective at performing this direct lignin hydrogenolysis in batch conditions, producing aromatic monomers close to the theoretical yield based on ether cleavage. Commonly produced monomers included phenylpropanol, propylphenol, and ethylphenol. In some cases, methylphenol, propenylphenol, and methoxylpropylphenol were also formed, depending on the reaction conditions. ${ }^{[1 \mathrm{~b}]}$ The choice of metal catalyst significantly affected the monomer selectivity. For instance, reactions catalyzed by $\mathrm{Ru} / \mathrm{C}$ in methanol produced methoxylated propylphenols with more than $90 \%$ selectivity whereas reactions with $\mathrm{Pd} / \mathrm{C}$ gave methoxylated phenylpropanols as the major products $(\sim 90 \%)$ because the metal's reduced oxophilicity reduced its ability to cleave the primary alcohol.[10a] Propylphenols were also the major product that was achieved when using $\mathrm{Ni}$ catalysts. ${ }^{[8 \mathrm{~b}]}$ Interestingly, the support that was employed also affected the product yields and distribution. Active carbon has been the most widely tested support and has been the most successful at facilitating the production of high yields (40-50\% from birch, which is close to theoretical yield) of aromatic monomers. A small number of studies used metal oxide supports $\left(\mathrm{Al}_{2} \mathrm{O}_{3}, \mathrm{Cu}-\mathrm{PMO}\right)$ and were able to achieve somewhat comparable yields (36-38\%) to those attained using activated carbon supports. ${ }^{[12]}$ The solvent also played an important role during hydrogenolysis. Protic solvents (methanol, ethanol, isopropanol, butanol, ethylene glycol) were able to dissolve and solvolyze lignin under the high temperatures that are used for these reactions, but in some studies, also served as the H-donor. ${ }^{[86,13]}$ Polar aprotic solvents such as dioxane, which are well known for their ability to solubilize lignin even at room temperature, have also been used in these direct hydrogenolysis processes and have been equally successful at producing high monomer yields $(40-50 \%) .[8 \mathrm{~b}, 9 \mathrm{~b}]$ However, the 
structure of these solvents precludes their dual use as a solvent and source of hydrogen.

Because the result of these RCF processes was generally a solid, cellulose-rich pulp mixed with a metal catalyst, catalyst separation has always been a major issue. To remedy this issue, $\mathrm{RCF}$ using a semi-continuous flow-through reactor was recently studied to alleviate this issue. In this case, the biomass and catalyst were packed in one or more separated columns and connected by tubing and switching valves. The solvent (usually methanol) was first pumped through the biomass bed to extract partially deconstructed lignin oligomers from the biomass matrix, which were then sent to the catalyst bed for hydrogenolysis. ${ }^{[14]}$ Such a method not only facilitated the separation of the cellulosic pulp from the catalyst after reaction by avoiding their contact in the first place, but also enabled the separate optimization of the lignin extraction and hydrogenolysis process conditions. In such conditions, reactive intermediates could still condense during extraction. However, with a fast-enough flow, these intermediates could reach the hydrogenation reactor faster than they could condense. The kinetic study of lignin extraction and hydrogenolysis suggested that lignin extraction or solvolysis was the limiting step under traditional RCF conditions and suggested that further efforts should be focused on increasing solvolysis kinetics to optimize the overall RCF method. ${ }^{[14 a]}$ In process conditions, the biomass bed would be periodically consumed and need to be reloaded between runs, making this process semi-continuous. Furthermore, the flow-through process typically consumes at least four times the quantity of solvent (often more) compared to batch conditions, which increases costs. ${ }^{[14 b, c]}$ All processes that use whole biomass in close proximity with a catalyst also have to face the issue of non-lignin biomass-derived impurities poisoning the catalyst. A notable issue involves the acetate groups on the hemicellulose, which are easily cleaved under RCF conditions and can poison the catalyst. Nevertheless, given the near-theoretical yields that are attainable and the possibilities that exist to recycle the solvent, semi-continuous flow-through processes are one of the options being explored for commercial scale-up. ${ }^{[15]}$

\subsection{Trapping Intermediates by Acetyl Formation}

During the cleavage of the $\beta-\mathrm{O}-4$ linkages, some reactive intermediates, such as enol ethers (compounds $\mathbf{1 0}$ and 13), and phenylacetaldehydes (compound $\mathbf{5}$ ), are formed under acidic or basic conditions, which can react with nucleophiles including lignin aromatic groups, which leads to condensation. A possible approach to minimizing these condensation pathways is to add agents that will react and trap these specific species before they can form $\mathrm{C}-\mathrm{C}$ linkages. Watanabe et al. used methanol as a trapping agent for enol ether intermediates (Scheme 2D and E). Methanol could react with enol ethers followed by dehydration and hydrolysis to form a ketone product (compound 14, Scheme 3A), or stable (di)methylated acetals (compound 15) during lignin decomposition in the presence of an acid catalyst and microwave irradiation (Scheme 3B). The resulting lignin oil was about $10 \mathrm{wt} \%$ of the raw biomass and contained about $20 \%$ of monomers and $80 \%$ oligomers, which is about one third of the lignin content. ${ }^{[16]}$ The significant remaining condensation and low monomer yield can likely be explained by the poor lignin solubility in the solvent and the other condensation mechanisms that are possible in acidic media and that are unaffected by methanol (for the mechanism in Scheme $2 \mathrm{~A}^{[5 c]}$ ). The nature of the reaction media had a large influence on the reaction results as no monomers were obtained when the solvent was changed from a hydrophobic solvent to a hydrophilic one.

Because some of the reactive intermediates are aldehydes $(e . g$. see Scheme 2B and E), which are formed in acidolysis conditions, Barta et al. proposed using diols to capture these intermediates. During triflic acid-catalyzed depolymerization of organosolv lignin, phenylacetaldehydes, which were important participants in
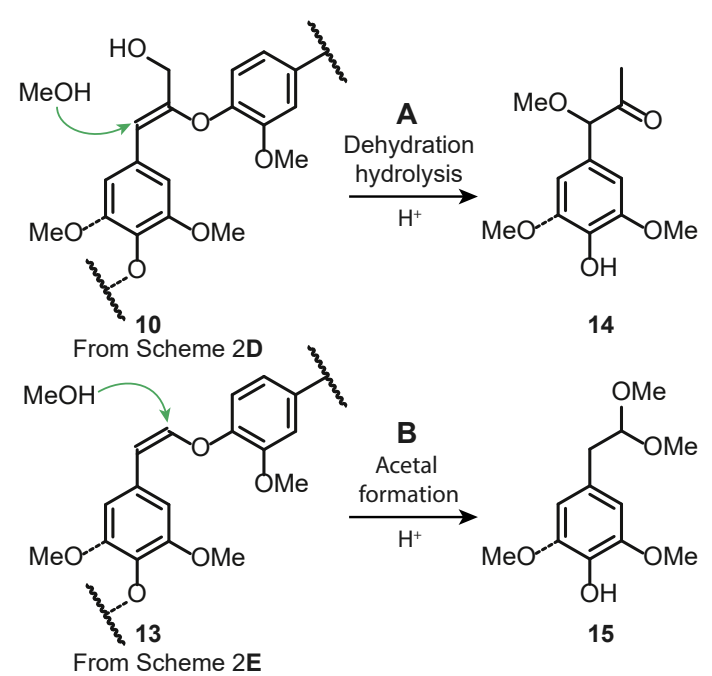

Scheme 3. Stabilization of reactive intermediates by methanol under acidic condition in hydrophobic media. Adapted from ref. [16].

unwanted side reactions, were captured by adding ethylene glycol to form relatively stable 5-membered ring acetals (Scheme 4). ${ }^{[17]}$ A study of a reaction with a simple $\beta-\mathrm{O}-4$ model compound (Scheme 4A) led to an approximate yield of $90 \%$ and a similar selectivity toward the acetal product. However, using a model compound with a three-carbon side chain (Scheme 4B) reduced the acetal yield to $35 \%$, which was probably because with the simpler model compound (shown in Scheme 4A), phenylacetaldehyde (compound $\mathbf{5}$ in Scheme 2E) was the major product, whereas with the veratrylglycerol- $\beta$-guaiacyl ether (compound 18), substantial quantities of Hibbert's ketone (compound 21, which is less likely to form cyclic acetals with diol due to its lower reactivity) was generated as well (Scheme 2D). When applying this approach to walnut dioxosolv lignin, only $9 \mathrm{wt} \%$ of monomers and oligomers were obtained. Using a Lewis acid (iron (III) triflate) instead of a Brønsted acid improved the overall yield of acetal products to $35 \mathrm{wt} \%$ from methanosolv lignin. ${ }^{[18]}$ 2-Naphthol has also been studied as a successful carbocation scavenger for lignin released during biomass pretreatment. In this case, the authors did not focus on lignin depolymerization but enzymatic hydrolysis of the polysaccharides, for which they observed a significant improvement (65\%) after saccharification after adding 2-naphthol. This improvement indicated the carbocations generated on lignin during acid pretreatment (compounds $\mathbf{9}$ and $\mathbf{1 0}$ in Scheme 2D) reacted with 2-naphthol, which avoided repolymerization of the lignin on cellulose and, thus, reduced enzyme deactivation. [19] However, the effect was to create $\mathrm{C}-\mathrm{C}$ linkages with lignin and so it was unlikely to facilitate improved lignin monomer production.

Importantly, the acid-catalyzed depolymerization of lignin is not limited to one cleavage mechanism but leads to several degradation and condensation mechanisms (Scheme 2A, D, and E). However, targeting only species such as aldehyde intermediates or enol ether intermediates (as discussed above) cannot prevent all of these pathways. Therefore, the targeting of only a select number of intermediates by these trapping strategies inherently limits the yields that are attainable, which is what has been observed in their corresponding studies.

\section{Preventing the Formation of Reactive Intermediates}

\subsection{Physically Preventing Reactive Intermediate Formation by Rapid Extraction in Flow-through Conditions}

As demonstrated above, trapping reactive intermediates during lignin depolymerization can significantly improve the yield of lignin derived oligomers and monomers. However, such 


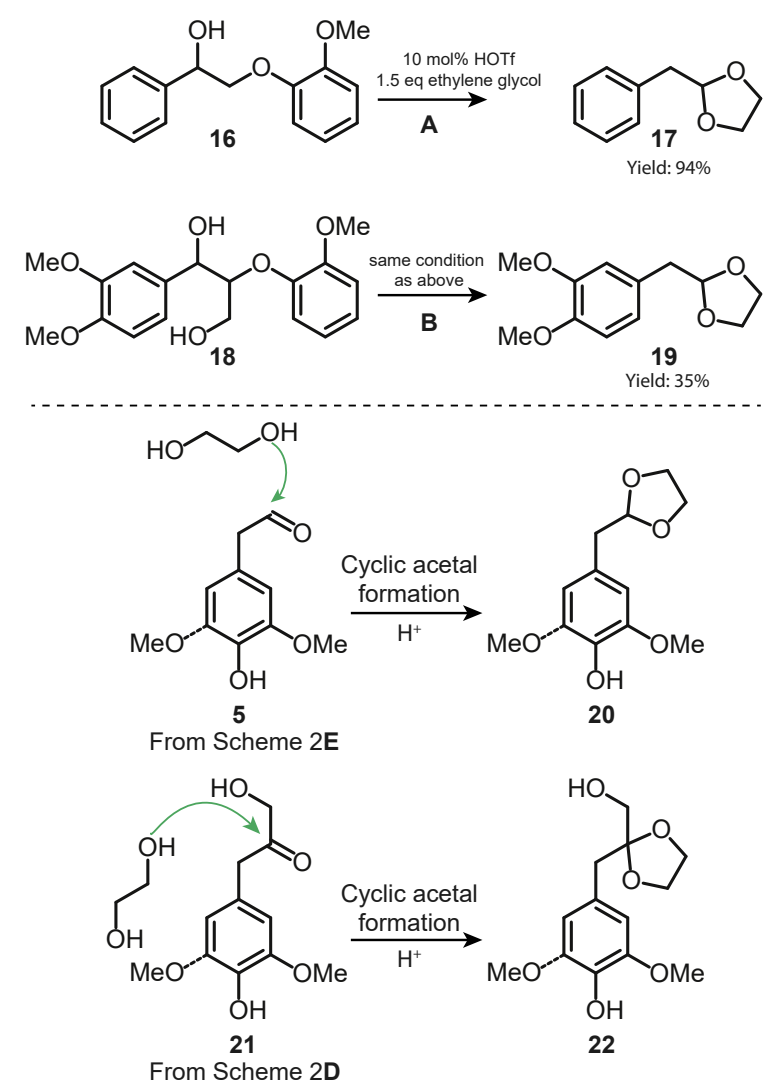

Scheme 4. Stabilization of reactive intermediates using ethylene glycol in acidic conditions. Adapted from ref. [17].

methods are still unable to approach theoretical yield because they often target only a fraction of the condensation mechanisms. The resulting yields are generally even worse when these methods are applied to lignin that has already been extracted because condensation has already occurred during the isolation process, which happens either in acidic or basic conditions that are conducive to degradation. In contrast, the RCF method is able to achieve high yield of monomers (close to theoretical yield) by starting from native lignin and using a stabilization method that targets nearly all condensation mechanisms. However, $\mathrm{RCF}$ often causes irreversible degradation or transformation (e.g. through hydrogenation) of the carbohydrate fractions, and leads to major challenges in catalyst recovery (even though a few studies were performed to address these issues by either isolating the catalyst or recovering it magnetically[12a,13a]). With these challenges in mind, an attractive solution would be to isolate biomass's lignin fraction while preserving the $\beta-\mathrm{O}-4$ and other ether linkages as much as possible. The most well-known approach to do so is to produce 'enzymatic' or 'cellulolytic' lignin, which is isolated only with enzymes and is regarded as having an essentially 'native' structure. ${ }^{[20]}$ However, this approach requires several extensive ball milling treatments interspersed with several enzymatic digestion steps, which makes it almost impossible to scale up.

An alternative way to extract lignin while preventing significant $\beta-\mathrm{O}-4$ degradation is to use the aforementioned flowthrough methods. Such methods are typically performed at high temperature with short retention times (i.e. high flow rates), which, unlike a batch-based pretreatment, are able to remove the reactive carbohydrates and lignin intermediates from the heated zone before condensation, and thereby diminish the undesired condensation. In other words, unlike in flow-through RCF described above, where condensation was quenched with hydrogenation, in simple flow-through, condensation is quenched by rapidly dropping the temperature. The partially preserved lignin could then be recovered by precipitation from the resulting solution. The feed solution can be hot water, dilute acid aqueous solutions, and organic solutions. Most of these studies, especially those using water, which is a poor lignin solvent, only focused on component fractionation and the effect of flow-through on subsequent polysaccharides hydrolysis, ${ }^{[21]}$ but did not investigate in detail the chemical structure alteration of the resulting lignin. ${ }^{[9 a, 22]}$ More recently, Dumesic et al. reported a flow-through fractionation method using a mixed $\gamma$-valerolactone $/ \mathrm{H}_{2} \mathrm{O}(80 / 20$, $\mathrm{v} / \mathrm{v})$ solvent containing dilute $\mathrm{H}_{2} \mathrm{SO}_{4}(0.05 \mathrm{wt} \%)$ and showed that the solvent significantly promoted the deconstruction of the biomass matrix, while very effectively dissolving the lignin. ${ }^{[22 \mathrm{~d}]}$ The resulting corn stover lignin could be deconstructed to up to $48 \%$ (carbon yield) after a hydrogenolysis process using concentrated $\mathrm{H}_{3} \mathrm{PO}_{4}$ in methanol over $\mathrm{Ru} / \mathrm{C}$, which indicated that the $\beta-\mathrm{O}-4$ linkages of the native lignin were well preserved.[9a] However, the overall lignin extraction yield was around $70 \%$, which led to an overall yield of $\sim 30 \%$, which was still below theoretical yields. The harshness of the conditions also led to a very large array of products. A formic acid/ $\mathrm{H}_{2} \mathrm{O}$ solution was also used for flow-through fractionation of wheat straw at $120-140{ }^{\circ} \mathrm{C}$ with a 15 min retention time.[22a] Using Heteronuclear Single Quantum Coherence (HSQC) NMR characterization, $84 \%$ of the $\beta-\mathrm{O}-4$ linkages were retained in the isolated lignin ( $44 \%$ in milled-wood lignin versus $38 \%$ in isolated lignin, per 100 aromatic units). However, only $62 \%$ of the native lignin was removed, of which only $44 \%$ could be recovered by precipitation in water (with the remainder being water-soluble lignin), which overall led to a low lignin recovery yield. The yield of lignin could be improved by using harsher conditions but this led to reduction of the $\beta-\mathrm{O}-4$ content (22\%). ${ }^{[22 \mathrm{a}]}$ Methanol was also used as the eluent to fractionate lignin from birch at $180-220{ }^{\circ} \mathrm{C}$ with $\mathrm{H}_{2}$. In this case, the lignin was solvolyzed into low molecular weight products with a yield of around $21 \mathrm{wt} \%$ monomers (based on Klason lignin). In summary, achieving high yields of lignin while preserving the native lignin structure is still a major challenge even when flowthrough conditions are used.

\subsection{Stabilization of $\beta-0-4$ Linkages by $\alpha-\mathrm{OH}$ Etherification}

As we learned from the mechanism of lignin repolymerization under acidic conditions, the $\alpha$-hydroxyl group is one of the most vulnerable functionalities in the $\beta-\mathrm{O}-4$ linkage and plays an important role in condensation reactions. This hydroxyl group is readily protonated and then dehydrated to generate a carbocation (Scheme 2D). Chemical stabilization of this $\alpha$-hydroxyl would thus be a promising approach to suppress repolymerization reactions. Westwood et. al. used a solution containing $n$-butanol, $5 \mathrm{wt} \%$ water, and $0.2 \mathrm{M} \mathrm{HCl}$ to fractionate lignocellulose and achieved very good separation of lignin. ${ }^{[23]}$ The resulting lignin contained large amounts of $\beta-\mathrm{O}-4$ linkages as characterized by HSQC NMR. Under the mild conditions $\left(<120{ }^{\circ} \mathrm{C}\right)$ they employed and with high concentrations of the alcohol, the $\alpha$-carbocations that were likely generated quickly reacted with the alcohol to form a relatively stable $\alpha$-butoxylated structure (compound 23, Scheme 5A), instead of being attacked by an aromatic carbanion (Scheme 2D). Depolymerization study of this obtained lignin by acidolysis with ethylene glycol trapping method (Scheme 4) generated 7-18 wt\% of acetal aromatic monomers depending on the wood species that was used.[23] This lower yield of monomer compared to other methods was probably due to the incomplete preservation of native $\beta-\mathrm{O}-4$ linkages and/or repolymerization during acidolysis. At the same time, hemicellulose structures were converted into butoxylated monosaccharides which were difficult to be transformed back into sugar molecules, which could cause issues for further utilization of the hemicellulose fraction. 


\subsection{Stabilization of $\beta-0-4$ Linkages by $\alpha-\mathrm{OH}$ Oxidation}

Selective oxidation of the same $\alpha-\mathrm{OH}$ in the $\beta-\mathrm{O}-4$ linkage to form a ketone is another approach to prevent the formation of $\alpha$-carbocation and therefore suppress the re-condensation in a later decomposition process. With this in mind, an oxidationhydrogenation two-step strategy to depolymerize lignin was investigated by Wang et al. The benzylic alcohol of native lignin still embedded in biomass was first oxidized to carbonyl groups using a DDQ/NHPI/NaNO, catalytic oxidation system (Scheme $5 \mathrm{~B})$. Then the newly formed ketone group within the $\beta-\mathrm{O}-4$ ether linkages were cleaved using a specifically tailored NiMO sulfite catalyst to produce aromatic monomers at an interesting yield (3.2 $\mathrm{mg}$ out of $50 \mathrm{mg}$ of birch powders containing $20 \mathrm{wt} \%$ lignin). ${ }^{[24]}$ However, this yield was lower than the yield obtained by other methods ${ }^{[25]}$ (which are described in detail below). Such oxidation processes are generally slow and thus rarely outpace degradation mechanisms, which likely explains the limited yields. Furthermore, this strategy suffers from similar catalyst recovery issue as most of the RCF procedures as it involves the physical mixing of biomass with homogenous and heterogeneous catalysts.

\subsection{Preventing Quinone Methide Formation by Methylation of the Phenolic Hydroxyl}

Quinone methides are not involved in primary degradation pathways but are critical reactants in secondary repolymerization reactions. ${ }^{[26]}$ Previous reports have suggested that these intermediates likely play a more important role than vinyl ethers in terms of repolymerization activity. ${ }^{[27]}$ This is likely due to quinone methides' extreme instability, which leads to them being readily attacked by nucleophiles at the double bond position, which generates high molecular weight products (Scheme 2C). Quinone methides (compound 7) are formed under neutral and basic conditions from the free-phenolic units. Selective stabilization of the phenolic units, notably by methylation, can avoid the formation of quinone methide and reduce the repolymerization reaction (Scheme 5C). Pyrolysis of phenol-methylated milled wood lignin (MWL) in isopropanol at $300{ }^{\circ} \mathrm{C}$ resulted in reduced char formation and higher oil yield, compared to the case using nonderivatized MWL. An electron paramagnetic resonance (EPR)

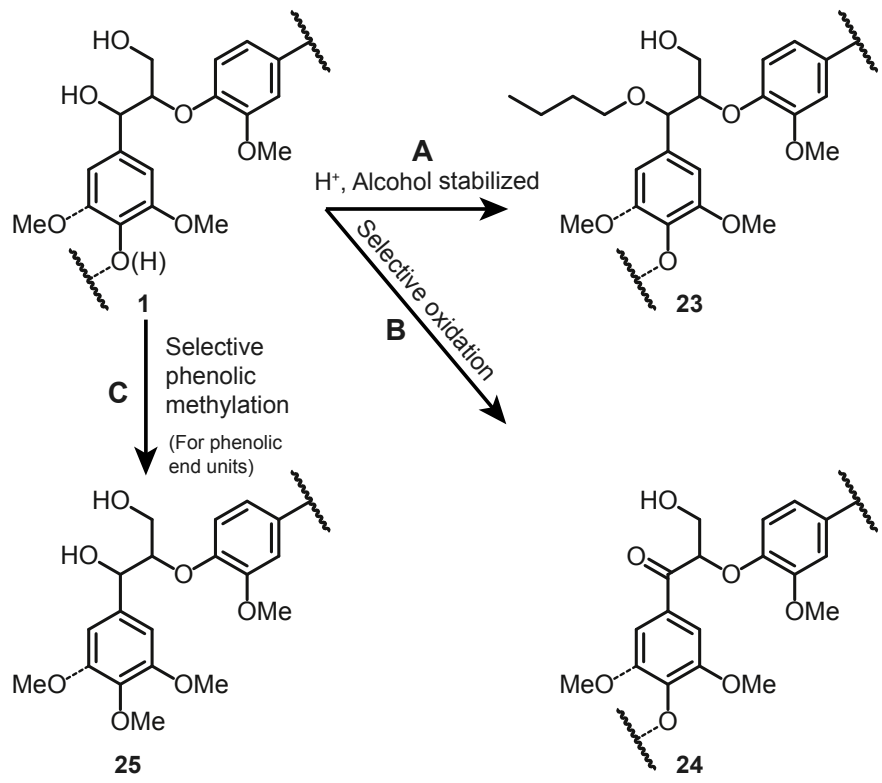

Scheme 5. Reactions used to suppress the formation of reactive intermediates. A Trapping the $\alpha$-carbocation by reaction with $n$-butanol under acidic conditions to prevent repolymerization. B Selective oxidation of the $\alpha-\mathrm{OH}$ to prevent dehydration and the subsequent carbocation formation. C Selective methylation of the phenolic hydroxyl to prevent the formation of quinone methides. Adapted from refs [23,24,28]. study of model lignin derivatives demonstrated that barely any free radicals were detected for the non-phenolic compounds at pyrolysis conditions. ${ }^{28]}$ Even though phenolic methylation can suppress lignin repolymerization under pyrolysis, any monomer yields achieved through this approach have been limited, likely because of the limited effect this strategy has had on alternate degradation mechanism. However, few studies have focused on the controlled depolymerization of methylated lignin (as opposed to pyrolysis conditions, which are fairly harsh and lead to uncontrolled reaction pathways) so further study would be warranted.

\subsection{Stabilization of the $\beta-0-4$ Linkage's Diol Structure by Acetal Formation}

More recently, our group has become interested in strategies to prevent $\beta-\mathrm{O}-4$ linkage condensation mechanisms. We discovered that adding formaldehyde during lignin extraction under acid condition could significantly suppress this condensation by reacting with the 1,3-diol structures of $\beta-\mathrm{O}-4$ linkages to form acetals while simultaneously reacting aromatic rings to trap any generated carbanions (Scheme 2D and E, Scheme 6). Hydrogenolysis of isolated stabilized lignin from beech gave $45 \%$ monomer yield by hydrogenolysis. This yield was close to the yield obtained by RCF of the untreated wood, and almost an order of magnitude higher than the control experiment performed without adding formaldehyde. ${ }^{[25 c]}$ Further study showed that the product selectivity can be significantly improved by simply tuning the functionalization. When using longer aldehydes like propionaldehyde or acetaldehyde, while optimizing the extraction and hydrogenolysis conditions, a selectivity to just two products (propanolsyringol and guaiacol) exceeded $90 \%$, while yields remained close to $50 \%$. Furthermore, when using a transgenic poplar (where the Ferulate 5-Hydroxylase had been overexpressed), the selectivity to a single product (propanolsyringol) reached $80 \% .{ }^{[25 \mathrm{~b}]}$ The longer aldehydes did not react with the aromatic ring and hence did not prevent carbanion formation but significantly increased product selectivity by avoiding the production of any alkylated monomers. The absence of any significant drop in yield when using propionaldehyde indicated that the formation of the acetal was likely the most important contributing factor to preventing repolymerization.

Another advantage of this approach was that it allowed efficient fractionation of the lignocellulosic substrate.[25a] The stabilized lignin was solubilized and easily separated. The hemicelluloses were depolymerized into monosaccharides (mainly xylose) that reacted with the aldehydes to form di-acetal functionalized sugars, which could be easily separated and defunctionalized with acid hydrolysis to recover more than $80 \%$ of the xylose, ${ }^{[25 b, c]}$ or directly converted to furfural using Brønsted acid catalysis. ${ }^{[29]}$ This fractionation left behind a highly purified cellulose that could be easily enzymatically hydrolyzed (over $90 \%$ of the glucan was recovered as glucose) when propionaldehyde was used.[25a]

Considering the remarkable ability of aldehydes to stabilize lignin's $\beta-\mathrm{O}-4$ linkages and produce an isolated and purified form of lignin, the propylidene-acetal-stabilized lignin represented an attractive substrate for exploring lignin depolymerization via an oxidative route. We developed a tailored catalytic oxidation system, which included $\mathrm{DDQ} / \mathrm{HNO}_{3} / \mathrm{O}_{2}$ in a wet organic solution, to selectively remove the acetal protection and oxidize the $\alpha-\mathrm{OH}$ (Scheme 6). ${ }^{[30]}$ As the oxidation rate appeared to be faster than that of acetal removal at the optimal conditions, the released $\alpha-\mathrm{OH}$ was rapidly oxidized into an $\alpha$-ketone, which prevented further side reactions in the same way as the aforementioned oxidation strategies. The oxidized lignin was then cleaved using a $\mathrm{HCOOH} /$ $\mathrm{NaOOCH}$ system to generate phenyl propane diones at a yield of $31-35 \%$ yield (compared to a hydrogenolysis yield of $45 \%$ ) with $>90 \%$ selectivity. This yield and selectivity of diketones was significantly higher than those achieved in previous studies, ${ }^{[31]}$ 


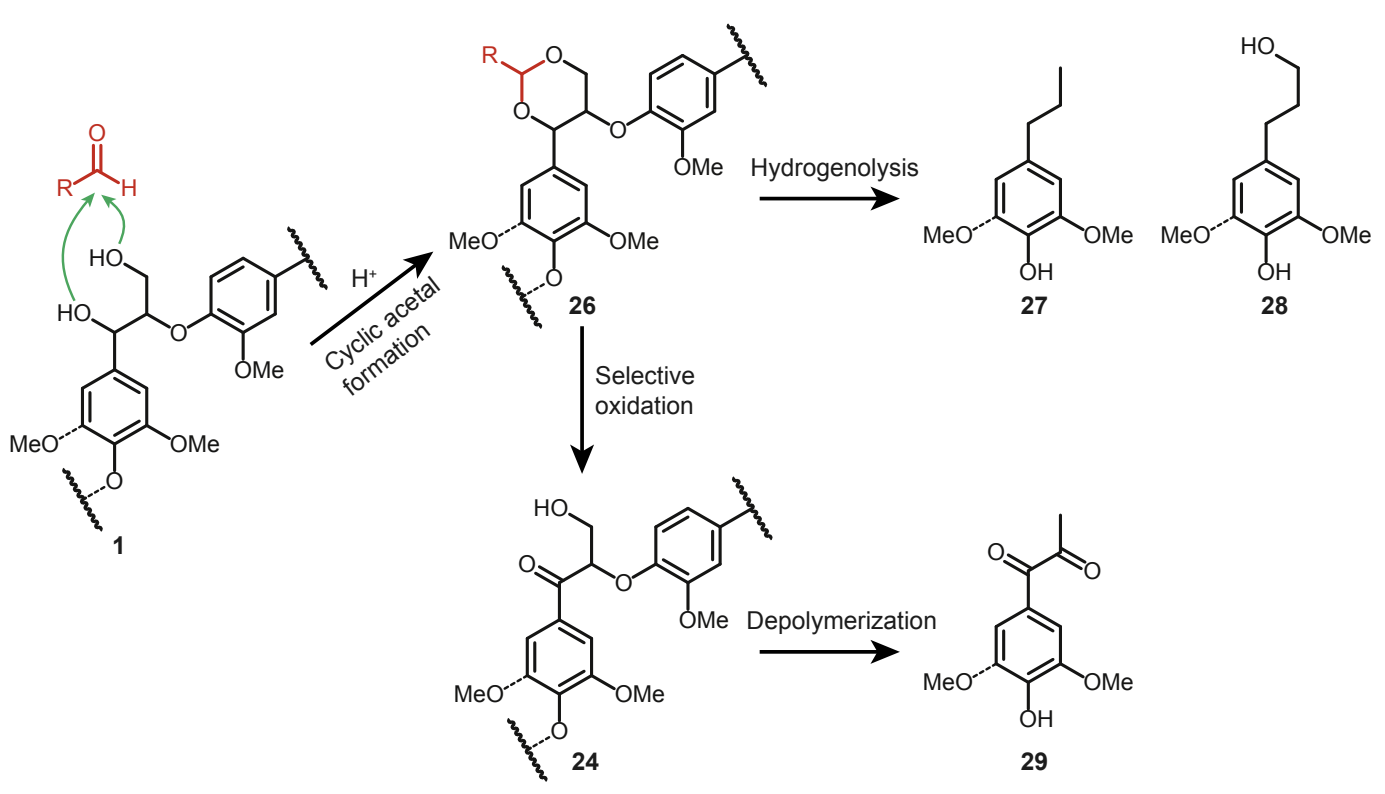

Scheme 6. Functionalization of the $\beta-\mathrm{O}-4$ linkages by diol functionalization with aldehydes under acidic conditions followed by two different methods to depolymerize the resulting lignin (hydrogenolysis and oxidation followed by depolymerization). Adapted from refs [25b,c,30].

which could mainly be attributed to the fact that $\beta-\mathrm{O}-4$ linkages were largely preserved during extraction and that oxidation immediately followed acetal removal, which prevented any significant degradation from occurring. This diol protection approach showed great efficacy for lignin isolation and depolymerization and scale-up and commercialization efforts are underway. Current challenges involve the use of undesirable solvents (e.g. dioxane) and the toxicity of aldehydes and their derivatives, which might hinder the development of large-scale applications. Further studies to improve this method will focus on using more environmental-friendly solvents and less toxic aldehydes.

\section{Conclusions and Perspectives}

In recent decades, various biorefinery methods have been developed for integrated utilization of lignocellulosic biomass. Valorization of lignin into chemicals has become an important focus of these efforts because lignin valorization will likely become an important aspect of the economic viability of any biorefining strategy. Recently, it has become clear that suppressing the undesirable side reactions, i.e. repolymerization, of lignin is an essential requirement for valorizing lignin as these reactions are the principle barrier to its exploitation. Specifically, preventing condensation reactions during lignin extraction and depolymerization has led to significant increases in the final monomer and short oligomer yields that could be produced. Strategies to prevent condensation have either focused on preventing the formation of reactive intermediates or rapidly converting the reactive intermediates into stable products. These approaches have led to some success but some issues still need to be addressed. First, processes that cannot achieve close to theoretical yields will be difficult to implement for cost reasons, which leave out most processes outside of those using RCF or aldehyde stabilization. Second, from a commercialization perspective, fully continuous reaction conditions are favored. Flow-through reaction conditions could allow for semi continuous operation of RCF by successively switching between biomass beds. However, significant condition optimization and catalyst deactivation/regeneration studies are still required to understand the possibilities of this approach. The aldehyde-based process is theoretically fully compatible with continuous operation but such conditions still need to be tested and, once again, catalyst deactivation/regeneration issues will need to be studied. Additionally, even though achieving high yields and selectivities of aromatic monomers is now possible from lignin, most of the resulting monomers that can be produced at reasonable yields including compounds 15, 20, 27, 28, and 29 (propyl guaiacol (27), might have a potential limited market as a foodgrade flavor) lack an actual market, i.e. there is often no direct application of these molecules. Therefore, further transformative steps will likely need to be developed to reach molecules that have an actual market.

Importantly, more than $50 \%$ of the lignin still results in less well-defined derivatives (e.g. oligomers) and further transformation and/or developments of these fractions will need to be explored. This large fraction of oligomers remains because all of the methods reviewed here have successfully focused on ether bond cleavage. However, a huge valorization opportunity remains if $\mathrm{C}-\mathrm{C}$ bond cleavage could be achieved selectively as this would facilitate extracting even more value from lignin. Some groups have already worked on this aspect and achieved certain success. ${ }^{[32]}$ Such methods could potentially also target technical lignins (which are significantly condensed) and thus could be rapidly integrated into existing industrial pulp and paper or biorefining processes. The successful implementation of such $\mathrm{C}-\mathrm{C}$ cleavage approaches would be a hugely important achievement. However, because most $\mathrm{C}-\mathrm{C}$ bonds result from random condensation processes, their cleavage will never yield products with the same selectivity as ether cleavage. Therefore, such developments, if they were to occur, would likely become complements, rather than replacements, to the ether cleavage methods reviewed here.

From a more general perspective, due to its status as the major natural reservoir of aromatic functionality, and due to the importance of such functionality in fine and bulk chemicals, lignin is unlikely to be bypassed in the development of a sustainable carbon economy. However, competing with the highly optimized and integrated petrochemical industry will be very challenging. In this context, processes involving chemical production from lignin must continue to become more efficient, to maximize its chances of being cost-effective and sustainable, and to ensure that there are societal incentives to drive the development of these technologies.

\section{Acknowledgements}

This work was supported by the Swiss Competence Center for Energy Research: Biomass for a Swiss Energy Future through the Swiss Commission for Technology and Innovation grant KTI.2014.0116.

Received: June 2, 2019

[1] a) R. Rinaldi, R. Jastrzebski, M. T. Clough, J. Ralph, M. Kennema, P. C. A. Bruijnincx, B. M. Weckhuysen, Angew. Chem. Int. Ed. 2016, 55, 8164, DOI: 10.1002/anie.201510351; b) W. Schutyser, T. Renders, S. Van den 
Bosch, S. F. Koelewijn, G. T. Beckham, B. F. Sels, Chem. Soc. Rev. 2018, 47, 852, DOI: 10.1039/c7cs00566k; c) C. Z. Li, X. C. Zhao, A. Q. Wang, G. W. Huber, T. Zhang, Chem. Rev. 2015, 115, 11559.

[2] a) W. Lan, J. Rencoret, F. C. Lu, S. D. Karlen, B. G. Smith, P. J. Harris, J. C. del Río, J. Ralph, Plant J. 2016, 88, 1046, DOI: 10.1111/tpj.13315; b) W. Lan, F. C. Lu, M. Regner, Y. M. Zhu, J. Rencoret, S. A. Ralph, U. I. Zakai, K. Morreel, W. Boerjan, J. Ralph, Plant Physiol. 2015, 167, 1284, DOI: 10.1104/pp.114.253757; c) W. Lan, K. Morreel, F. Lu, J. Rencoret, J. C. del Río, W. Voorend, W. Vermerris, W. Boerjan, J. Ralph, Plant Physiol. 2016, 171, 810, DOI: 10.1104/pp.16.02012.

[3] a) W. Boerjan, J. Ralph, M. Baucher, Annu. Rev. Plant Biol. 2003, 54, 519, DOI: 10.1146/Annurev.Arplant.54.031902.134938; b) J. Ralph, G. Brunow, P. J. Harris, R. A. Dixon, P. F. Schatz, W. Boerjan, in 'Recent Advances in Polyphenol Research', Vol. 1, Eds. F. Daayf, A. El Hadrami, L. Adam, G. M. Ballance, Wiley-Blackwell Publishing, Oxford, UK, 2008, p. 36.

[4] a) J. Ralph, K. Lundquist, G. Brunow, F. Lu, H. Kim, P. F. Schatz, J. M. Marita, R. D. Hatfield, S. A. Ralph, J. H. Christensen, Phytochem. Rev. 2004, 3, 29; b) F. X. Yue, F. C. Lu, S. Ralph, J. Ralph, Biomacromolecules 2016, 17, 1909

[5] a) S. Y. Jia, B. J. Cox, X. W. Guo, Z. C. Zhang, J. G. Ekerdt, ChemSusChem 2010, 3, 1078, DOI: 10.1002/cssc.201000112; b) B. J. Cox, S. Y. Jia, Z. C. Zhang, J. G. Ekerdt, Polym. Degrad. Stabil. 2011, 96, 426, DOI: 10.1016/j. polymdegradstab.2011.01.011; c) M. R. Sturgeon, S. Kim, K. Lawrence, R. S. Paton, S. C. Chmely, M. Nimlos, T. D. Foust, G. T. Beckham, Acs Sustain. Chem. Eng. 2014, 2, 472, DOI: 10.1021/Sc400384w.

[6] a) K. Shimada, S. Hosoya, T. Ikeda, J. Wood Chem. Technol. 1997, 17, 57, DOI: 10.1080/02773819708003118; b) J. Gierer, I. Noren, S. Wannstrom, Holzforschung 1987, 41, 79, DOI: 10.1515/hfsg.1987.41.2.79.

[7] a) S. B. Baker, H. Hibbert, J. Am. Chem. Soc. 1948, 70, 63, DOI: 10.1021/ ja01181a020; b) C. P. Brewer, L. M. Cooke, H. Hibbert, J. Am. Chem. Soc. 1948, 70, 57, DOI: 10.1021/ja01181a018; c) J. M. Pepper, H. Hibbert, J. Am. Chem. Soc. 1948, 70, 67, DOI: 10.1021/ja01181a021

[8] a) J. Z. Chen, F. Lu, X. Q. Si, X. Nie, J. S. Chen, R. Lu, J. Xu, ChemSusChem 2016, 9, 3353, DOI: 10.1002/cssc.201601273; b) Q. Song, F. Wang, J. Y. Cai, Y. H. Wang, J. J. Zhang, W. Q. Yu, J. Xu, Energ. Environ. Sci. 2013, 6, 994, DOI: 10.1039/c2ee23741e.

[9] a) J. S. Luterbacher, A. Azarpira, A. H. Motagamwala, F. Lu, J. Ralph, J. A. Dumesic, Ener. Environ. Sci. 2015, 8, 2657, DOI: 10.1039/c5ee01322d; b) N. Yan, C. Zhao, P. J. Dyson, C. Wang, L. T. Liu, Y. Kou, ChemSusChem 2008, 1, 626, DOI: $10.1002 /$ cssc. 200800080 .

[10] a) S. Van den Bosch, W. Schutyser, S. F. Koelewijn, T. Renders, C. M. Courtin, B. F. Sels, Chem. Commun. 2015, 51, 13158, DOI: 10.1039/ c5cc04025f; b) M. V. Galkin, A. T. Smit, E. Subbotina, K. A. Artemenko, J. Bergquist, W. J. J. Huijgen, J. S. M. Samec, ChemSusChem 2016, 9, 3280, DOI: $10.1002 /$ cssc.201600648; c) X. M. Huang, J. D. Zhu, T. I. Koranyi, M. D. Boot, E. J. M. Hensen, ChemSusChem 2016, 9, 3262, DOI: 10.1002/ cssc. 201601252.

[11] S. Van den Bosch, W. Schutyser, R. Vanholme, T. Driessen, S. F. Koelewijn, T. Renders, B. De Meester, W. J. J. Huijgen, W. Dehaen, C. M. Courtin, B. Lagrain, W. Boerjan, B. F. Sels, Energ. Environ. Sci. 2015, 8, 1748, DOI: 10.1039/c5ee00204d.

[12] a) S. Van den Bosch, T. Renders, S. Kennis, S. F. Koelewijn, G. Van den Bossche, T. Vangeel, A. Deneyer, D. Depuydt, C. M. Courtin, J. M. Thevelein, W. Schutyser, B. F. Sels, Green Chem. 2017, 19, 3313, DOI: 10.1039/c7gc01324h; b) Z. H. Sun, G. Bottari, A. Afanasenko, M. C. A. Stuart, P. J. Deuss, B. Fridrich, K. Barta, Nat. Catal. 2018, 1, 82, DOI: 10.1038/s41929-017-0007-z

[13] a) P. Ferrini, R. Rinaldi, Angew. Chem. Int. Ed. 2014, 53, 8634, DOI: 10.1002/anie.201403747; b) T. Renders, E. Cooreman, S. Van den Bosch, W. Schutyser, S. F. Koelewijn, T. Vangeel, A. Deneyer, G. Van den Bossche, C. M. Courtin, B. F. Sels, Green Chem. 2018, 20, DOI: 10.1039/c8gc01031e.

[14] a) E. M. Anderson, M. L. Stone, M. J. Hulsey, G. T. Beckham, Y. RomanLeshkov, ACS Sustain. Chem. Eng. 2018, 6, 7951, DOI: 10.1021/ acssuschemeng.8b01256; b) E. M. Anderson, M. L. Stone, R. Katahira,
M. Reed, G. T. Beckham, Y. Roman-Leshkov, Joule 2017, 1, 613, DOI: 10.1016/j.joule.2017.10.004; c) I. Kumaniaev, E. Subbotina, J. Savmarker, M. Larhed, M. V. Galkin, J. S. M. Samec, Green Chem. 2017, 19, 5767, DOI: 10.1039/c7gc02731a.

[15] W. N. Delgass, R. Agrawal, F. H. Ribeiro, B. S. L. Yohe, M. M. Abu-Omar, T. Parsell, P. J. Dietrich, I. M. Klein, US 9, 783, 474 B2, 2017.

[16] A. Kaiho, M. Kogo, R. Sakai, K. Saito, T. Watanabe, Green Chem. 2015, 17, 2780.

[17] P. J. Deuss, M. Scott, F. Tran, N. J. Westwood, J. G. de Vries, K. Barta, J. Am. Chem. Soc. 2015, 137, 7456.

[18] P. J. Deuss, C. S. Lancefield, A. Narani, J. G. de Vries, N. J. Westwood, K. Barta, Green Chem. 2017, 19, 2774, DOI: 10.1039/c7gc00195a.

[19] T. Pielhop, G. O. Larrazabal, M. H. Studer, S. Brethauer, C. M. Seidel, P. R. von Rohr, Green Chem. 2015, 17, 3521.

[20] J. Rencoret, P. Prinsen, A. Gutierrez, A. T. Martinez, J. C. del Río, J. Agric. Food Chem. 2015, 63, 603, DOI: 10.1021/jf505808c.

[21] a) S. Bhagia, H. J. Li, X. D. Gao, R. Kumar, C. E. Wyman, Biotechnol. Biofuels 2016, 9, DOI: ARTN 24510.1186/s13068-016-0660-5; b) C. G. Liu, C. E. Wyman, Ind. Eng. Chem. Res. 2003, 42, 5409, DOI: 10.1021/ ie $030458 \mathrm{k}$; c) L. S. Yan, L. B. Zhang, B. Yang, Biotechnol. Biofuels 2014, 7 , DOI: Artn 7610.1186/1754-6834-7-76.

[22] a) H. Zhou, L. P. Tan, Y. J. Fu, H. Y. Zhang, N. Liu, M. H. Qin, Z. J. Wang, ChemSusChem 2019, 12, 1213, DOI: 10.1002/cssc.201802803; b) S. Singh, G. Cheng, N. Sathitsuksanoh, D. Wu, P. Varanasi, A. George, V. Balan, X. D. Gao, R. Kumar, B. E. Dale, C. E. Wyman, B. A. Simmons, Front. Energy Res. 2015, DOI: UNSP 6210.3389/fenrg.2014.00062; c) H. L. Wang, H. X. Ben, H. Ruan, L. B. Zhang, Y. Q. Pu, M. Q. Feng, A. J. Ragauskas, B. Yang, ACS Sustain. Chem. Eng. 2017, 5, 1824, DOI: 10.1021/acssuschemeng.6b02563; d) J. S. Luterbacher, J. M. Rand, D. M. Alonso, J. Han, J. T. Youngquist, C. T. Maravelias, B. F. Pfleger, J. A. Dumesic, Science 2014, 343, 277.

[23] C. S. Lancefield, I. Panovic, P. J. Deuss, K. Barta, N. J. Westwood, Green Chem. 2017, 19, 202, DOI: $10.1039 / \mathrm{c} 6 \mathrm{gc02739c}$

[24] C. F. Zhang, H. J. Li, J. M. Lu, X. C. Zhang, K. E. MacArthur, M. Heggen, F. Wang, ACS Catal. 2017, 7, 3419, DOI: 10.1021/acscatal.7b00148.

[25] a) M. T. Amiri, G. R. Dick, Y. M. Questell-Santiago, J. S. Luterbacher, Nat Protoc. 2019, 14, 921, DOI: 10.1038/s41596-018-0121-7; b) W. Lan, M. T. Amiri, C. M. Hunston, J. S. Luterbacher, Angew. Chem. Int. Ed. 2018 57, 1356, DOI: 10.1002/anie.201710838; c) L. Shuai, M. T. Amiri, Y. M. Questell-Santiago, F. Heroguel, Y. D. Li, H. Kim, R. Meilan, C. Chapple, J. Ralph, J. S. Luterbacher, Science 2016, 354, 329, DOI: 10.1126/science. aaf7810.

[26] V. M. Roberts, V. Stein, T. Reiner, A. Lemonidou, X. B. Li, J. A. Lercher, Chem. Eur. J. 2011, 17, 5939, DOI: 10.1002/chem.201002438.

[27] T. Nakamura, H. Kawamoto, S. Saka, J. Wood Chem. Technol. 2007, 27, 121, DOI: $10.1080 / 02773810701515143$.

[28] K. H. Kim, T. Dutta, E. D. Walter, N. G. Isern, J. R. Cort, B. A. Simmons, S. Singh, ACS Sustain. Chem. Eng. 2017, 5, 3913, DOI: 10.1021/ acssuschemeng.6b03102.

[29] Y. M. Questell-Santiago, R. Zambrano-Varela, M. T. Amiri, J. S. Luterbacher, Nat. Chem. 2018, 10, 1222, DOI: 10.1038/s41557-018-0134-4.

[30] W. Lan, J. B. de Bueren, J. S. Luterbacher, Angew. Chem. Int. Ed. 2019, 58 , 2649, DOI: 10.1002/anie.201811630.

[31] a) A. Das, A. Rahimi, A. Ulbrich, M. Alherech, A. H. Motagamwala, A Bhalla, L. D. Sousa, V. Balan, J. A. Dumesic, E. L. Hegg, B. E. Dale, J. Ralph, J. J. Coon, S. S. Stahl, ACS Sustain. Chem. Eng. 2018, 6, 3367, DOI: 10.1021/acssuschemeng.7b03541; b) A. Rahimi, A. Ulbrich, J. J. Coon, S. S Stahl, Nature 2014, 515, 249.

[32] a) L. Shuai, J. Sitison, S. Sadula, J. H. Ding, M. C. Thies, B. Saha, ACS Catal. 2018, 8, 6507; b) L. Dong, L. Lin, X. Han, X. Si, X. Liu, Y. Guo, F. Lu, S. Rudic, S. F. Parker, S. Yang, Y. Wang, Chem. 2019, DOI: j.chempr.2019.03.007.

[33] S. Y. Jia, B. J. Cox, X. W. Guo, Z. C. Zhang, J. G. Ekerdt, Holzforschung 2010, 64, 577, DOI: 10.1515/Hf.2010.075. 